\title{
Prevalence and risk factors of thyroid dysfunction in young age
}

\author{
Yuliya Molokanova ${ }^{1, *}$, Vladimir Saprykin ${ }^{1}$, Irina Lyalina ${ }^{1}$ \\ ${ }^{1}$ Moscow Region State University, 10A, Radio str, 105005, Moscow, Russia
}

\begin{abstract}
We examined people aged from 17 to 22 on the state of the thyroid gland. Analyzed results of the ultrasonography, laboratory test data, health assessment questionnaires and food records of the 300 study participants. Risk factors of thyroid dysfunction development for young people were analyzed. Signs of structural changes of the thyroid gland were detected amongst $57 \%$ of study participants. The laboratory test results confirmed $44 \%$ of the primary outcome received after palpation and ultrasonography. As a result $67 \%$ of the examined volunteers from the in need of treatment group and $35 \%$ intact volunteers were transferred into the group of dynamic follow-up thyroid gland monitoring. Discovered a less number of cases of the structural and/or functional thyroid disorders amongst people who have lived for 5 years in ecologically clean regions. All study participants had chronic alimentary iodine insufficiency which didn't allow us to confirm the fundamental role of the iodine deficiency in the thyroid gland dysfunction development amongst young people. Laboratory confirmed diagnoses autoimmune thyroid disorders were found only amongst volunteers that consumed less than $1 / 4$ of the daily dose of iodine and lived in ecologically unsafe districts.
\end{abstract}

\section{Introduction}

The problem of endocrine diseases is urgent for most countries of the world, including the Russian Federation and Moscow region, in particular. The diagnosis of endocrine diseases is relevant due to its significant prevalence in the population and its social significance [1].

In 2015 in the Russian Federation were registered more than 1,500,000 patients with the first ever diagnosis of endocrine system disease. In 2017 this number increased by 100,000 . From 2017 to the end of 2018 the morbidity rate among the population of the Russian Federation for first-time diagnosed endocrine system diseases increased by a factor of 2.9. A similar trend has been discovered in the Moscow region. The level of primary endocrine pathology in the Moscow region increased by 4.3 times while in Moscow it increased by more than 10 times [2].

Among the endocrine system diseases the second place after diabetes belongs to thyroid diseases. Unfortunately, this indicator is steadily increasing. In the last four years the number of the first detected thyroid diseases has increased by $12 \%$ [3].

\footnotetext{
* Corresponding author: 89236613134@inbox.ru
} 
The reasons for such dynamics are iodine deficiency, unfavorable heredity, pituitary gland and hypothalamus pathologies, less spread - unfavorable environmental factors of the place of residence [4]. Iodine deficiency, found in the regions of the Russian Federation, is of particular concern. According to world statistics, iodine deficiency is the only widespread cause of mental development disorders and brain damage that can be prevented [5]. However, despite the progress made worldwide in preventing iodine deficiency diseases in recent decades, it continues to be an unresolved problem [6,7].

Currently in Russia iodine deficiency diseases are registered amongst $10-15 \%$ of the urban population and $13-35 \%$ of the rural population. At the same time, the level of iodine consumption by the population is three times lower than a recommended norm [8]. Chronic nutritional iodine deficiency is accompanied by an overstress of adaptation mechanisms and the development of iodine deficiency pathologies of varying severity (Table 1).

Table 1. Commonly occuring variety of the iodine deficiency disorder depending on iodine intake (P. Laurberg, 2001) [9].

\begin{tabular}{|l|l|l|}
\hline \multicolumn{1}{|c|}{$\begin{array}{c}\text { Iodine deficiency Iodine } \\
\text { deficiency }\end{array}$} & Median ioduria & \multicolumn{1}{c|}{ Diseases Diseases variety } \\
\hline SevereSevere & $<25 \mathrm{mkg} / \mathrm{l}$ & $\begin{array}{l}\text { - Malformation of the neural system } \\
\text { - Reproductive system dysfunction } \\
\text { - High rate of child mortality } \\
\text { - Goiter } \\
\text { - Hypothyroidism } \\
\text { - Thyrotoxicosis }\end{array}$ \\
\hline Medium & $25-60 \mathrm{mkg} / \mathrm{l}$ & $\begin{array}{l}\text { Thyrotoxicosis amongst middle and older age } \\
\text { groups }\end{array}$ \\
\hline Mild & $60-120 \mathrm{mkg} / \mathrm{l}$ & Thyrotoxicosis amongst older age groups \\
\hline $\begin{array}{l}\text { Normal iodine Optimal } \\
\text { iodine consumption }\end{array}$ & $120-220 \mathrm{mkg} / \mathrm{l}$ & \multicolumn{1}{c}{-} \\
\hline
\end{tabular}

Effective iodine deficiency prevention involves eating foods that are rich and/or enriched with iodine. However, in terms of the number of households consuming sufficiently iodine-enriched foods, Russia belongs to the third group of countries. Foods rich and enriched with iodine are consumed by $20 \%-50 \%$ of households [8]. This requires mass prevention of alimentary iodine deficiency in the population. One of the difficulties in implementing this task is the lack of food culture in the population, as well as poor awareness of the risks associated with the inadequate consumption of foods containing sufficient iodine [10].

Because of the urgency of the stated problem, we checked the condition of the thyroid gland amongst young people and studied the risk factors for the development of thyroid gland diseases among people of young age. The hypothesis of the study based on the fact that students have morphological and physiological problems of the thyroid gland due to different reasons, including the ecological status of the place of residence and daily iodine consumption. We examined 300 volunteers aged 17-23 years, 1st-5th year students of Moscow State Regional University. The work was conducted in 2018-2019.

\section{Methods}

From the variety of recommended examination methods for thyroid function detection [11], we used the following:

- Interviews to compile anamnesis. Also, each participant kept a detailed food diary for three weeks, which allowed determining the average daily dose of iodine intake of each volunteer. 
- Examination and palpation of the thyroid gland in the sitting and lying position. Ultrasonography is the main instrumental method to determine the exact size, volume, mass of the thyroid gland as well as its blood supply. The instrumental examination was carried out with the S9Pro ultrasound diagnostic device.

- Laboratory tests to assess the ratio of hormones: thyreotrophin (TTH) - the hormone of the pituitary which regulates the production of hormones by the thyroid gland, free triiodothyronine (free T3) - thyroid hormone, which controls oxidation process in cells and tissues, free thyroxin (free T4) - thyroid hormone which regulates protein metabolism. In case of signs of morphological thyroid pathology after ultrasound examination, we recommended additional antibody blood tests to thyroglobulin and thyroid peroxidase to detect the autoimmune disorders in the thyroid gland.

\section{Results}

Residents of 27 cities/areas of the Moscow region took part in the study. Having assessed the ecological status of the territory of respondents' residence [12], we discovered the following. In ecologically unfavourable areas have been permanently living $83,33 \%$ of volunteers for more than 5 years. Among them $53.33 \%$ - in "heavily contaminated" areas; $28.89 \%$ - in "contaminated" areas; $1.11 \%$ - in the slightly contaminated area. $16.67 \%$ of the study participants lived in environmentally friendly conditions. Of those, $3.33 \%$ - in "slightly polluted" areas, $6.67 \%$ - in "fairly clean" areas, 5.56\% - in "clean" areas and $1.11 \%$ - in "particularly clean" areas.

Examination, palpation and subsequent ultrasound scan of the volunteers' thyroid gland showed the following. About $43 \%$ of the examined volunteers had no obvious deviations in thyroid morphology - "morphological norm" (Figure 1). Approximately 24\% of the examined volunteers had "minor morphological deviations from the norm": uneven parenchymal echogenicity, evident hyperemia etc. (Figure 2, 3). Clear signs of "morphological pathology": cysts, nodes, etc. - were found among 33\% of the examined volunteers. (Figure 4).

Blood tests for hormones and antibodies recommended for evaluation of the functional state of the thyroid gland allowed to clarify the results of ultrasound diagnostics. In particular, laboratory results confirmed $75 \%$ of diagnoses of "morphological norm", $33 \%$ of diagnoses of "minor morphological deviations from norm" and 43\% of "morphological pathology" detected through ultrasound diagnostics. However, about $35 \%$ of favorable results after ultrasound diagnostics were disproved by the laboratory test results.

All study participants provided detailed food diaries with a three-week diet. After analyzing these data, it was found that $63 \%$ of the volunteers ate foods rich in iodine at least twice a week, $36 \%$ ate these foods at least once a week, and $1 \%$ ate such foods less than once a week. By calculating the average daily dose of iodine consumed with food it was confirmed that all study participants had chronic alimentary iodine deficiency. In particular, $50 \%$ of the volunteers received $1 / 4$ of the daily norm of iodine , $43 \%$ - consumed no more than $1 / 2$ of the daily norm of iodine, just over $2 \%$ of the volunteers consumed $3 / 4$ of the daily norm of iodine, about $4.5 \%$ of the volunteers consumed more than $3 / 4$ of the daily norm of iodine. The recommended norm of the average daily amount of iodine - 150-200 $\mathrm{mkg}$ /day - was not consumed by any participant of the study. 

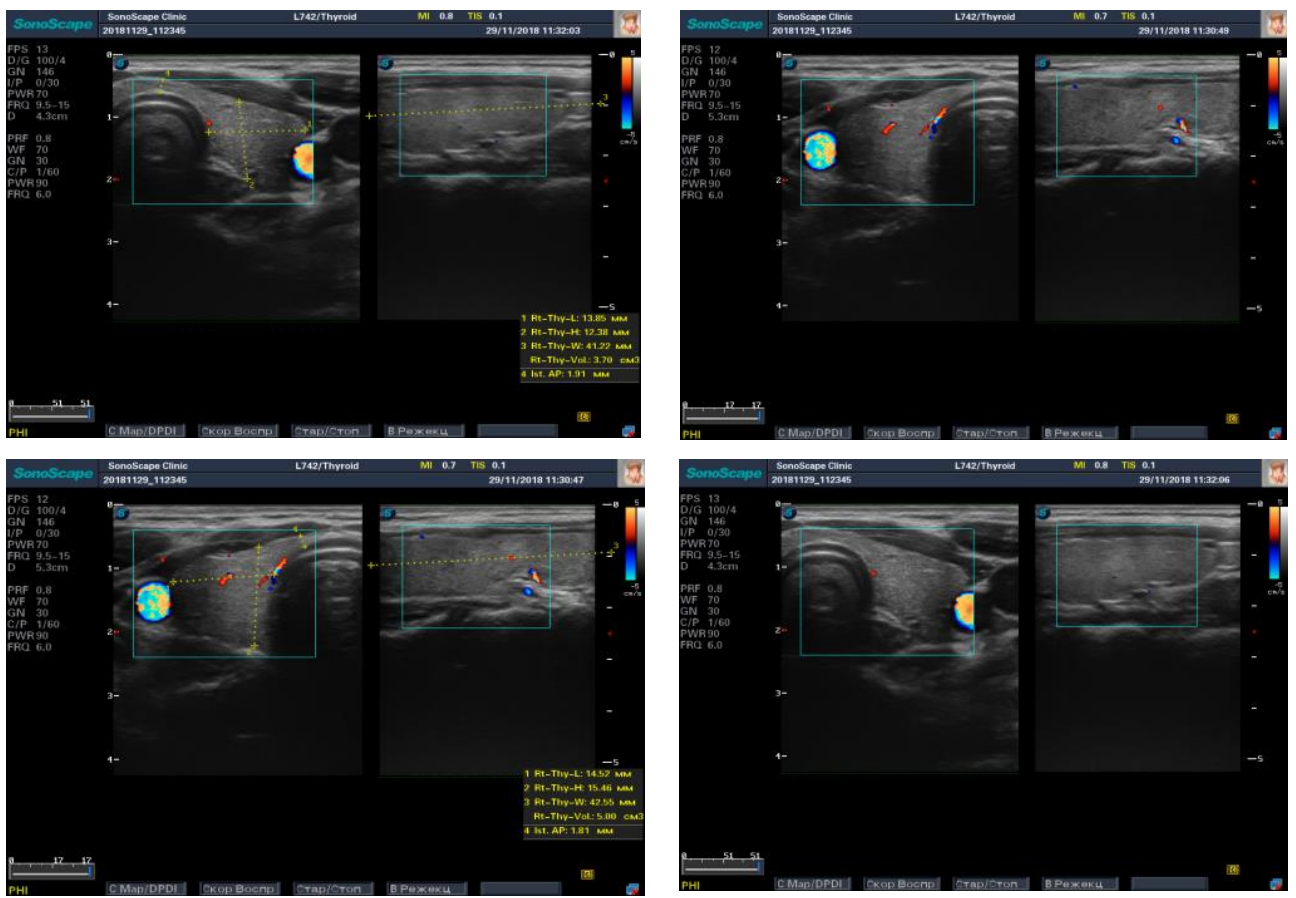

Fig. 1. Ultrasound image of the morphological norm of the thyroid gland (photo was made by S9Pro ultrasound diagnostic device).
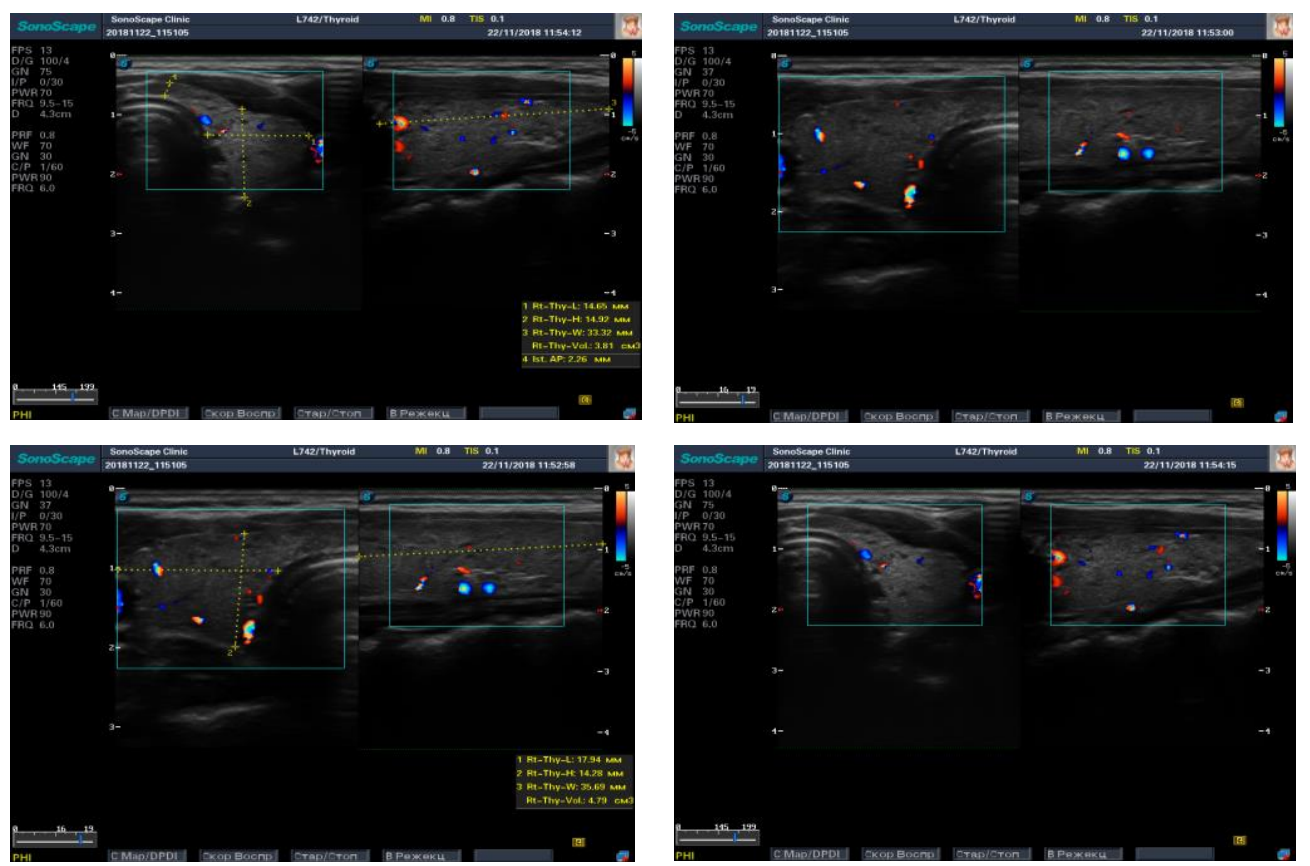

Fig. 2. Ultrasound image of the significant morphological thyroid gland deviations from the norm uneven parenchymal echogenecity (photo was made by S9Pro ultrasound diagnostic device). 

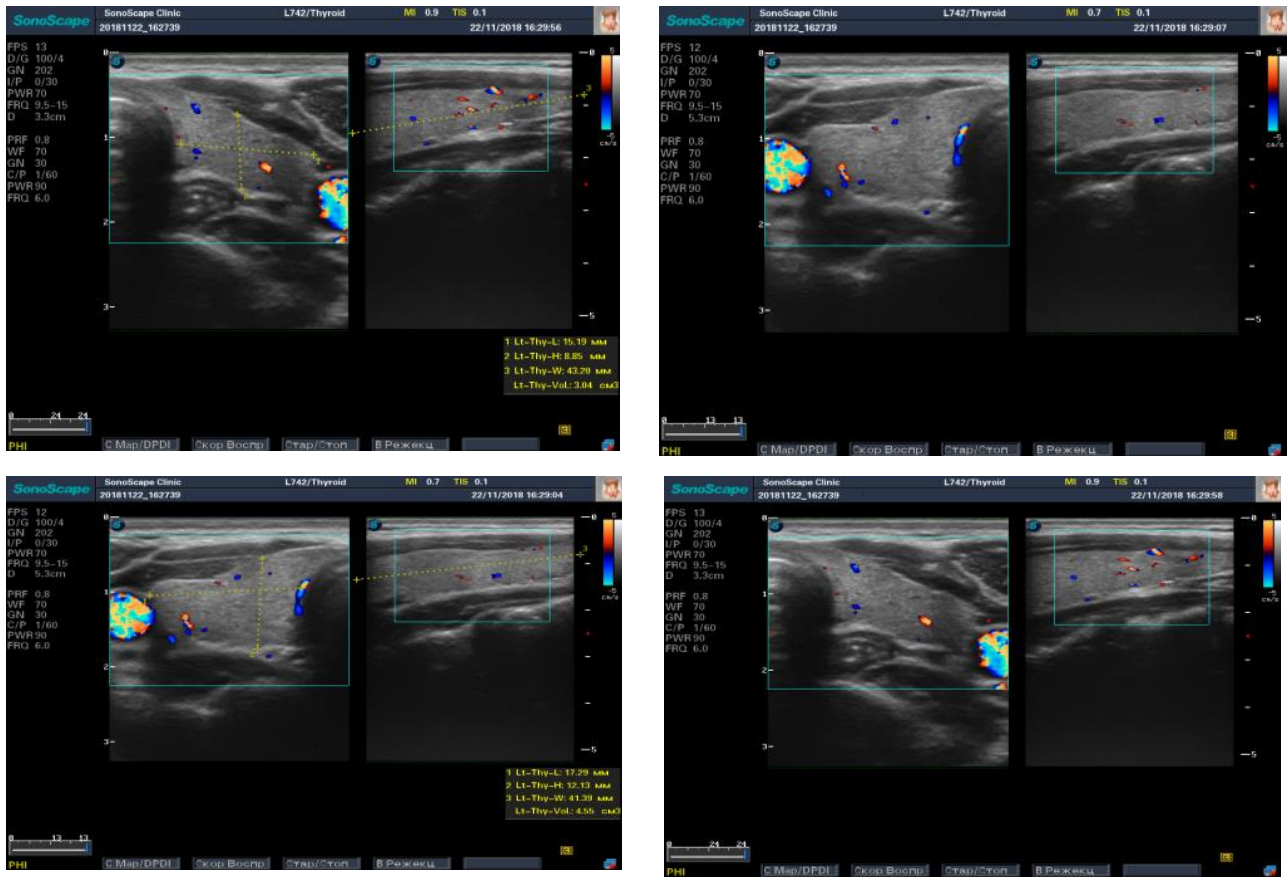

Fig. 3. Ultrasound image of the significant morphological thyroid gland deviations from the norm diffusive increase of blood flow (photo was made by S9Pro ultrasound diagnostic device).

Thyroadenitis
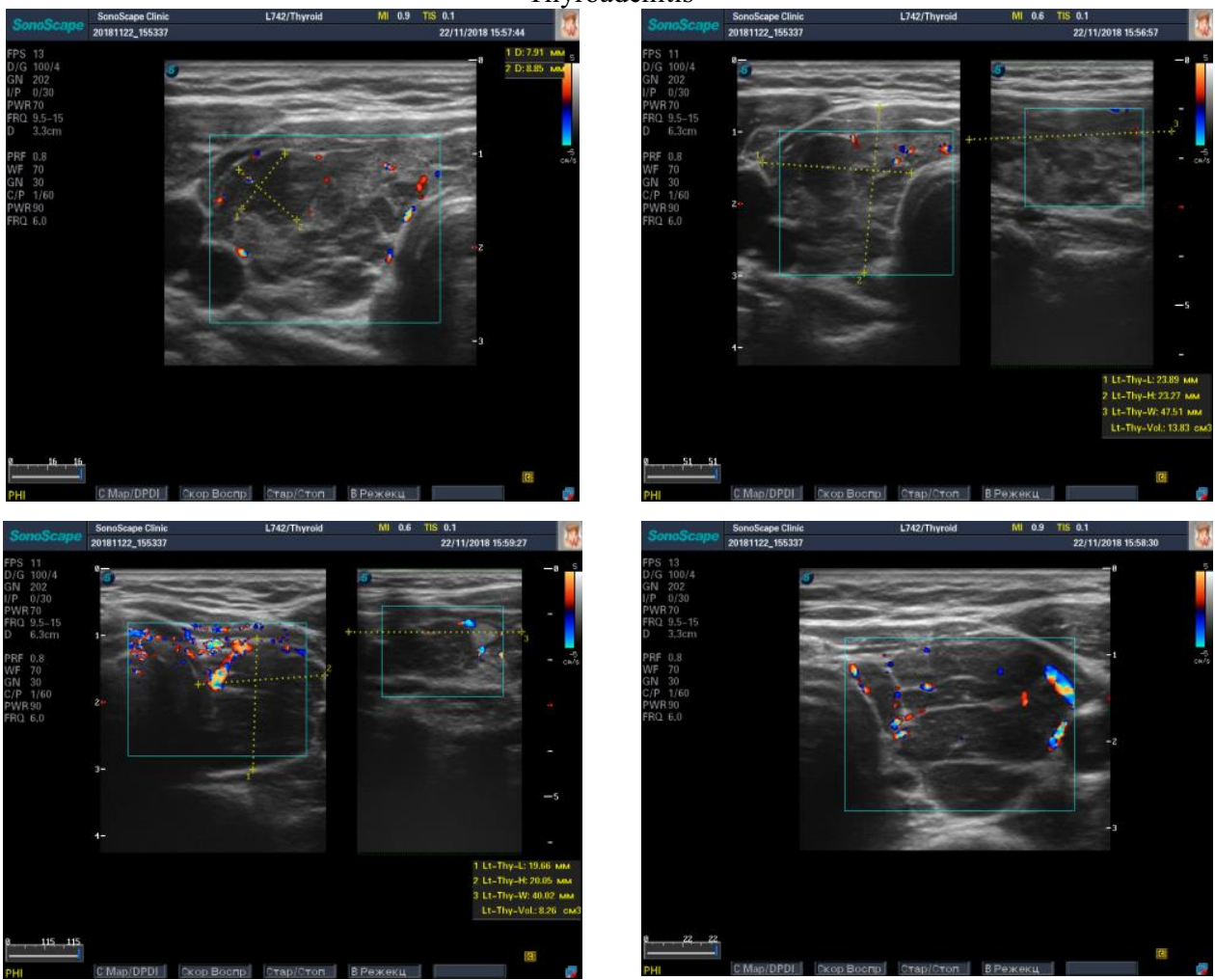

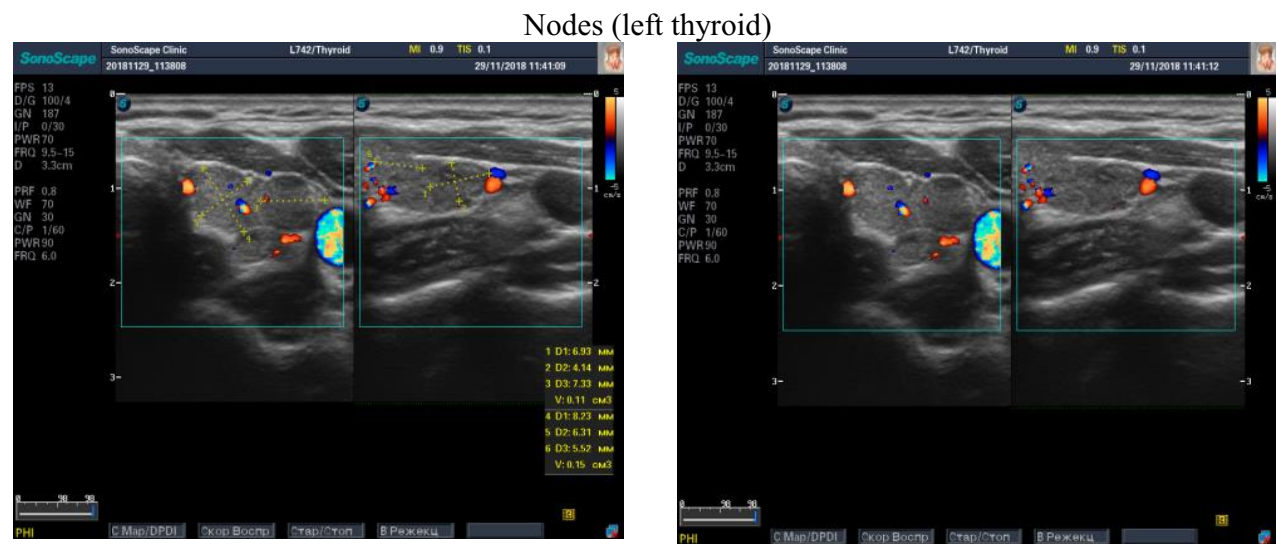

Fig. 4. Ultrasound image of the significant morphological thyroid gland deviations - thyroadenitis, nodes (photo was made by S9Pro ultrasound diagnostic device).

\section{Discussion}

Since the Moscow region is an iodine deficient biogeochemical province, all study participants were in equal conditions by this criterion. In addition, all the volunteers are in the group of alimentary iodine deficiency, that is, in equal conditions on this criterion as well. It would be logical to assume that morphological abnormalities and thyroid pathology would be more frequently registered among volunteers from environmentally disadvantaged areas. As can be seen from Table 1, this statement is not quite correct. In ecologically unfavorable areas of residence, cases of "morphological norm" and "morphological pathology" of the thyroid gland were in almost equal proportions. In ecologically favorable areas was found a statistically significant difference between cases of "morphological norm" and "morphological pathology" of the thyroid gland. In addition, cases of morphological pathology of the thyroid gland were authentically less frequently registered among people from ecologically favorable areas of residence than among people from ecologically unfavorable places of residence (Table 2).

Table 2. Correlation of the thyroid gland condition and ecological well-being of the places of residence of the volunteers.

\begin{tabular}{|c|c|c|c|}
\hline \multicolumn{1}{|c|}{ Thyroid gland condition } & Morphological & $\begin{array}{l}\text { Minor } \\
\text { morphological } \\
\text { deviations from } \\
\text { the norm }\end{array}$ & $\begin{array}{l}\text { Morphological } \\
\text { pathology }\end{array}$ \\
\hline $\begin{array}{l}\text { Number, } \\
\text { unfavorable districts } \\
\text { residence }\end{array}$ & 36,00 & 25,33 & $38,67^{\mathbf{\Delta}}$ \\
\hline $\begin{array}{l}\text { Namber, \%, ecologically favorable } \\
\text { districts }\end{array}$ & $66,67^{*}$ & 26,67 & $6,67^{\mathbf{4}}$ \\
\hline $\begin{array}{l}\mathbf{\Delta} \text { the difference between numbers is statistically significant if the p-value is equal to } \mathrm{P} \leq 0,05 . \\
* \text { the difference between numbers is statistically significant if the p-value is equal to } \mathrm{P} \leq 0,01 .\end{array}$ \\
\hline
\end{tabular}

The significance of the environmental factor in relation to the population' thyroid disease incidence has not been proven by academic medicine [3]. Nor have we been able to identify a clear correlation between the degree of the ecological pollution of the place of residence and the condition of the volunteers' thyroid gland. Nevertheless, the obtained results do not allow completely exclude the influence of the ecological component from the group of risk factors of thyroid gland pathology development. 
The results of laboratory diagnostics made corrections to ultrasound scan data, disproving an average of $44 \%$ of primary diagnoses. At the same time $67 \%$ of the examined volunteers from the group in need of treatment and 35\% from the group of healthy were transferred to the group of dynamic thyroid monitoring. This confirms once again the necessity of a comprehensive diagnosis.

Alimentary iodine deficiency revealed among all study participants, however, does not confirm the primary role of iodine deficiency in the development of thyroid pathology. In particular, among volunteers consuming no more than $1 / 4$ of the daily iodine norm, more than $63 \%$ had no morphological or laboratory signs of thyroid gland malformation. Among volunteers consuming $1 / 2$ of the daily dose of iodine, about $40 \%$ had signs of thyroid gland pathology.

The ambiguousness of the results may be related to the young age of the volunteers. In 17-22 years the organism is still growing and developing, while having very flexible compensation and adaptation mechanisms. Comparatively large share of volunteers with signs of pathology revealed among people consuming $1 / 2$ of daily iodine norm can be related to such risk factor as autoimmune disorders. Many specialists note a significant contribution of autoimmune disorders to the growth of thyroid disease incidence among population [1, 7, 11]. According to our data, laboratory confirmed diagnoses of autoimmune thyroid diseases were registered only among volunteers consuming less than $1 / 4$ of the daily dose of iodine. In addition, they all live in ecologically unfavorable areas.

\section{Conclusion}

The conducted research showed the urgency of the problem of the increase of thyroid disease incidence in the population. Morphological and/or laboratory signs of forming or already evident thyroid gland pathology are registered in $69 \%$ of cases among young people. A mandatory laboratory tests for hormones and antibodies is required to clarify the primary diagnosis and exclusion of the possibility of autoimmune development.

We can consider multifactorial causation of thyroid diseases development. Among the risk factors, a special place is occupied by chronic alimentary iodine deficiency, revealed among all the volunteers surveyed. This requires mass prevention of iodine deficiency initiated at the national level. The influence of the ecological status of places of residence for the development of thyroid diseases in the population has not been statistically confirmed, but we could not completely deny the importance of this factor in our study. Significantly fewer cases of morphological and functional deviations and pathologies of the thyroid gland have been registered among volunteers from ecologically favorable places of residence. In addition, all cases of autoimmune diseases of the thyroid gland, registered in the course of the study, were found in people from environmentally disadvantaged areas experiencing severe chronic alimentary iodine deficiency.

\section{References}

1. N.M. Platonova, Klinicheskaya i eksperimental'naya tireoidologiya 11(1), 12 (2015)

2. Zdravoohranenie v Rossii.: Stat.sb. Rosstat. (M., 2019)

3. Izvestiya 1 (2017) https://iz.ru/660787/valeriia-nodelman/vse-bolshe-rossiian-stradaiutproblemami-s-shchitovidnoi-zhelezoi

4. V.M. Krasnov, Pediatricheskaya farmakologiya 7(1), 108 (2010)

5. I.I. Dedov, Deficit joda - ugroza zdorov'yu i razvitiyu detej Rossii: Nacional'nyj doklad (M., 2006) 
6. J.L. Eaton, Thyroid Disease and Reproduction (Springer Nature Switzerland AG, 2019)

7. M. Luster, L.H. Duntas, L. Wartofsky, The Thyroid and Its Diseases (Springer International Publishing AG, 2019)

8. I.I. Dedov, Profilaktika i lechenie jododeficitnyh zabolevanij v gruppah povyshennogo riska (M., Medicina, 2004)

9. I.E. Sapozhnikova, B.F. Nemcov, Vyatskij medicinskij vestnik 2-3, 27 (2007)

10. Y.P. Molokanova, V.P. Saprykin, Aktual'nye problemy biologicheskoj i himicheskoj ekologii: sb. mat. VI Mezhdunarodnoj nauchno-prakticheskoj konferencii (M., IIU MGOU, 2019)

11. E.A. Valdina, Zabolevaniya shchitovidnoj zhelezy: Rukovodstvo. Seriya «Sputnik vracha» (SPb, Piter, 2006)

12. Ekologicheskaya karta Moskovskoj oblasti, http://www.centrgeologiya.ru/jekologicheskaja-karta-moskovskoj-oblasti.html 